\title{
Evidence for Extant Life on Mars and Gilbert Levin
}

\section{Wickramasinghe $\mathrm{NC}^{1,2}$}

${ }^{1}$ Buckingham Centre for Astrobiology (BCAB), Buckingham University, UK

${ }^{2}$ Churchill College, Cambridge CB3 OHA, UK

Corresponding author: Wickramasinghe NC, Buckingham Centre for Astrobiology (BCAB), Buckingham University, UK, Tel: +44-777-838-9243; E-mail: ncwick@gmail.com

Received date: July 26, 2016; Accepted date: July 27, 2016; Published date: August 03, 2016

Copyright: $\odot 2016$ Wickramasinghe NC. This is an open-access article distributed under the terms of the Creative Commons Attribution License, which permits unrestricted use, distribution, and reproduction in any medium, provided the original author and source are credited.

\section{Editorial}

Exactly 40 years ago to the day, on 20 July 1976, the Viking lander, Viking 1, separated from the orbiter and touched down on the surface of Mars.

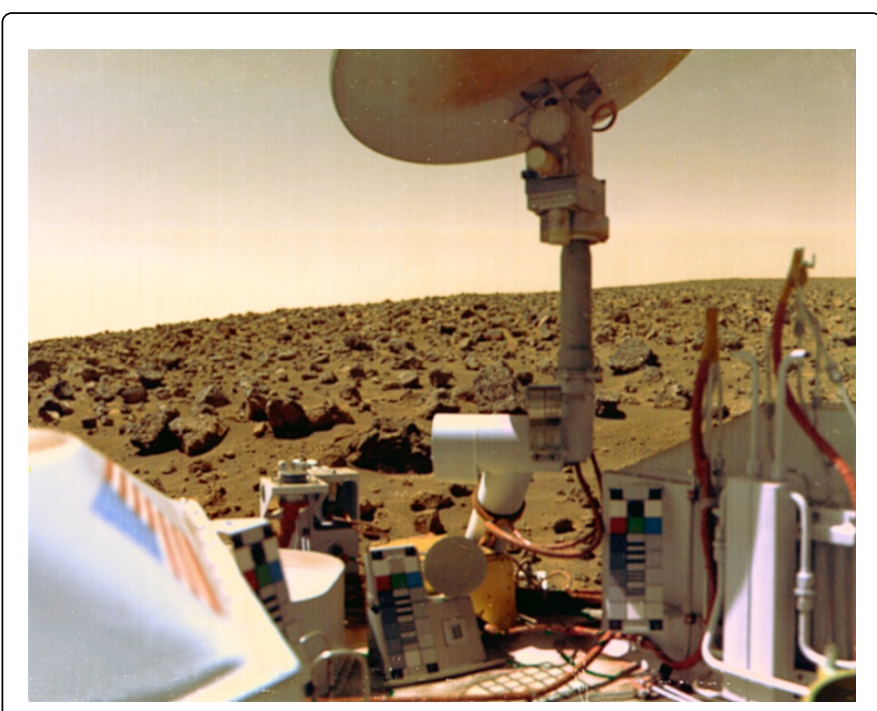

Figure 1: NASA Viking Labelled Release Experiment that showed evidence of life in July 1976 (Courtesy NASA).

A major goal of the space probes Viking 1 and Viking 2, the latter which landed on $3^{\text {rd }}$ September 1976, was to search for the existence of microbial life on Mars. In one experiment (Viking Labelled Release Experiment) led by Principal Investigator Gilbert Levin, biological tests were done in situ on samples of soil [1]. The presumption was that any microorganisms which may be present had metabolic processes broadly similar to those of terrestrial microorganisms. The soil was treated with various nutrients, and expelled gases and the soil itself were examined in several ways.

Four soil samples, one of which from underneath a rock, were tested and all produced positive results, within the range of results expected for soils on Earth. Heating the samples to above normal sterilization temperatures completely destroyed the activity, thus confirming that the initial positive result was biological not chemical. This was an important control for the experiment. An initially confusing discovery was that the Martian soil at the landing site did not show detectable amounts of organic compounds within the limitations of the equipment used (Viking GC/MS experiment). To err on the side of caution NASA scientists announced in 1976 that the Viking results were inconsistent with life, and that some other explanation was required to explain the vigorous gas release that was observed. As it transpired this was a mistaken judgement that led to a succession of wrong decisions being made in the later planning of Mars missions.

In 1986 and again in 2012 a careful re-examination of all the 1976 data led to the startling (but little publicised) conclusion that the Viking results may have indicated a positive result for primitive life in sub-surface niches on Mars [2]. What is true beyond doubt is that the results of the 1976 Viking experiments remain at the very least fully consistent with the presence of microbial life on Mars.

Since 1976 there been many space missions to Mars. They have now found evidence of seasonal water flows, dried-up river beds as well as methane on the surface and in the upper atmosphere, all of which suggest that microorganisms could still be thriving in specialised niches close to the surface.

It is a sad commentary on the sociology of modern science that the 1976 Viking life-detection experiment, or one similar to it, was not included in later missions to Mars. There is a touch of irony in that future sample-return endeavours, in which rock samples will be brought back to Earth, include elaborate "planetary protection" measures to take care of the contingency that microorganisms might be brought back from Mars-even, perhaps, microbes that may be pathogenic to humans.

NASA's Curiosity Rover has confirmed beyond any doubt the existence of seasonal liquid water flows on Mars as well as ample evidence for the organics that were thought missing in the GC/MS experiments in the Viking Mission. If extant Martian life is finally confirmed and acknowledged it can only be regarded as a long overdue confirmation of a discovery already made by Levin and Straat [1]. Their fulsome recognition for this most important scientific discovery is long overdue.

\section{References}

1. Levin GV, Straat PA (1976) Viking Labeled Release Biology Experiment: Interim Results. Science 194: 1322-1329.

2. Bianciardi G, Joseph MD, Ann SP, Gilbert L ( 2012) Complexity Analysis of the Viking Labeled Release Experiments. IJASS 13: 14-26. 